Urška Jeglic

\title{
Zaupanje do halal izdelkov in halal proizvodnje pri muslimanih v Republiki Sloveniji
}

\section{Trust in Halal Products and Halal Production among Muslims in Slovenia}

Povzetek: Halal industrija je začela počasi cveteti pred tridesetimi leti, ko se je na svetovnem trgu začelo množično uveljavljanje halal inšpekcij in posledično izdajanje halal certifikatov ter označevanje izdelkov z njim. V začetku 21. stoletja je Islamska skupnost v Republiki Sloveniji podelila prve certifikate slovenskim podjetjem, med katerimi prevladujejo podjetja z mesno industrijo. Vsi muslimani v Sloveniji se prehranjevanja po halal predpisih ne držijo. Prav tako vsi muslimani ne kupujejo izdelkov s halal certifikatom. Članek predstavlja stanje zaupanja muslimanov v Sloveniji v halal izdelke in halal industrijo. Na podlagi opravljene raziskave je mogoče reči, da glede na zaupanje v halal izdelke in halal proizvodnjo obstajajo tri različne skupine muslimanov.

Ključne besede: halal, halal certifikati, halal izdelki v Sloveniji, halal prehrana, zaupanje muslimanov

Abstract: The halal industry began to flourish 30 years ago with the mass introduction of halal controls and the subsequent halal certification and labelling of products. At the beginning of the 21st century, the Islamic Community in the Republic of Slovenia awarded the first certificates to Slovenian companies operating mainly in the meat industry. Not all Muslims in Slovenia adhere to the halal diet. Also, not all Muslims buy halal-certified products. This article presents how Muslims in Slovenia trust halal products and the halal industry. Based on the research conducted, we observe that there are three distinct groups of Muslims in terms of their trust in halal products and a halal production.

Keywords: halal, halal certificate, halal products in Slovenia, halal diet, the trust $\mathrm{f}$ Muslims 


\section{Uvod}

Islam se po številu vernikov na svetu uvršča na drugo mesto, takoj za krščanstvom. Število njegovih pripadnikov se ocenjuje na 1,6 milijard, od tega jih v Evropi živi 45 milijonov. Od 232 svetovnih držav je islam državna religija v 57 državah. Muslimane v Evropi je mogoče razdeliti na tri skupine: avtohtone evropske muslimane (prim. Balkan) in celoto migrantov, ki so registrirani bodisi kot tujci bodisi kot državljani države, v kateri živijo in delajo (Khader 2016, 174). Večina slovenskih muslimanov ima svoje korenine v Bosni in Hercegovini, Črni gori, Albaniji in Severni Makedoniji ter na Kosovu. Skupaj s sezonskimi delavci bi naj v Sloveniji živelo 70.000 muslimanov (Grabus 2011).

Prehranjevanje po halal predpisih je ena izmed najbolj prepoznavnih islamskih verskih praks. Temelji zanjo so postavljeni v Koranu, verska izročila pa so v prvih generacijah podala jasnejše smernice, katero hrano je muslimanom dovoljeno jesti in katere ne. $V$ zaključku bomo videli, da se prehranjevalne navade muslimanov razlikujejo, različno pa je tudi zaupanje muslimanov v halal proizvodnjo.

\section{Halal prehrana}

Beseda halál (arab. حلال, halāl') pri muslimanih označuje vse stvari, ki so glede na pravne predpise dopustne, harám (arab. حَرَام ,harām') pa pomeni prepovedi. Halal je vse, s čimer je Alah zadovoljen, kar vključuje tudi vsa etična dejanja, najpogosteje pa se $v$ neislamski literaturi povezuje s hrano, ki jo muslimani smejo uživati. Omeniti je sicer treba, da obstajajo določene vrste hrane, pri katerih lahko vsak musliman sam izbere, ali jih bo užival ali ne. Takšna vrsta hrane se imenuje mubah (arab. مباح). Zadnja kategorija je prehrana makruh (arab. مكروه), ki je zavržna, ni pa prepovedana, kar pomeni, da jo je bolje ne uživati.

Večina islamskih učenjakov se strinja, da je prepovedano vse, kar je del prašiča: meso, mast, koža, dlake in kosti. Po Koranu $(6,145)$ je svinjina nekaj odvratnega in grešnega. Mleko drugih kopenskih živali se lahko uživa le, če so čiste. Poseben status ima pri halal hrani čredna živina: ovce, koze, govedo, kamele (K 6, 134-44; 16, 5). Kopitarje, med katere prištevamo konje, osle in mulo, obravnava Koran kot živali, ki so namenjene za ježo ali so za okras (K 16, 8). Nikjer v Koranu pa ni zapisano, ali jih je jesti dovoljeno ali ne, zato so mnenja glede tega ambivalentna. Velja tudi, da se ne sme jesti živali s členki (lev, tiger, volk, medved, lisica itn.). Dovoljeno je uživati tudi ptice, mnenja pa si nasprotujejo glede ujed. Koran dovoljuje uživanje vseh vodnih živali $(K 5,96 ; 35,12)$, a med pravnimi šolami obstajajo različni pogledi - mnenje ni enotno glede uživanja morskih živali, ki niso ribe (sipe, lignji, školjke, raki, drugi morski sadeži), in glede mrtvih rib, ki so poginile brez znanega razloga (Pollak 2007, 34-36). Da muslimani meso živali lahko jedo, morejo biti te zaklane po islamskih predpisih. Žival se zakolje tako, da se ji venska žila in karotidna arterija prereže z ostrim nožem, saj se na takšen način doseže največji pretok krvi, posledično žival tudi najmanj trpi. Med klanjem živali je treba izgovoriti Alahovo ime. 
Koran $(5,3)$ pravi, da je vernikom prepovedano jesti »meso poginule živali, svinjsko meso in vse, kar je zaklano v imenu koga drugega, in ne Alaha, ter žival, ki je poginila zaradi davljenja, udarcev, padca z višine ali zaradi vbodov z rogovi, in to, kar je načela zver, razen če še živo zakoljete, ter to, kar je zaklano na oltarjih. « Med haram prehrano se prištevajo tudi alkoholne pijače in jedi, ki vsebujejo alkohol. Če se alkohol spremeni v kis, ga je dovoljeno uživati, ni pa dovoljeno piti sadnega soka, če ta zavre (Pollak, 2007, 33). Zavračanje alkoholnih pijač temelji na prepričanju, da je alkohol sam po sebi nečist, saj vinjenost vernike omejuje pri molitvi. Če človek uživa alkohol, je lahko torej kaznovan (prav tam, 37). Po drugi strani je bil v zgodovini odnos do alkohola veliko bolj dinamičen, o čemer razpravlja tudi Shahab (2017).

Islam pozna še eno zapoved, povezano s prehrano - post. Ta tretji steber islama je zapovedan za vse zdrave muslimane od pubertete naprej. „Cilj vsakega muslimana je, da bi ugajal Bogu in dosegel nebesa. Ugajati Bogu pomeni ljubiti ga, se ga bati in ga ubogati. " (Osredkar 2019, 661) Lahko bi rekli, da je prehranjevanje po islamskih predpisih za muslimane ena od poti za ugajanje Alahu. Toda bolj sekularizirani muslimani se predpisov islamskega prehranjevanja ne držijo, ker v omenjeni zapovedi ne vidijo smisla.

\section{Halal certifikati}

Muslimani so se več kot tisočletje prehranjevali po predpisih halal prehrane, ne da bi bila ta označena s halal certifikatom - prehranjevali so se zlasti z lokalno hrano. Označevanje hrane s halal certifikatom je začelo postajati smiselno po prodoru zahodnega tipa oglaševanja tudi v islamske države in z migracijami muslimanov v nemuslimanske države. Pri tem je glavno težavo predstavljalo kupovanje mesa, saj se v zahodnih državah živali ne kolje po islamskih predpisih. Tudi pri nas 25 . člen Zakona o zaščiti živali prepoveduje, da bi se žival usmrtilo brez vnaprejšnje omamitve. Muslimani so tako sprva zahajali v trgovine s košer prehrano.

Rekli bi lahko, da so na halal proizvodnjo najprej vplivale množične migracije, zanemariti pa ne gre niti, da so halal certifikati v zadnjih 20. letih postali dobičkonosen posel tudi v islamskih državah. Konec 20 . stoletja so k rasti halal industrije pripomogle tudi bolezni živali, predvsem bolezni krav in fibromuskularna displazija.

Izdelki s halal certifikatom imajo na svoji embalaži odtisnjen ustrezen logotip. Ker za izdajo certifikatov obstaja več inšpekcij, je na svetovnem trgu možno najti paleto različnih logotipov, ki pa večinoma nosijo napis halal v arabščini in polmesec. Halal certifikat označuje, da produkt ne vsebuje nobenih surovin prepovedanih živali in da so bile živali ubite po halal predpisih. Ob tem velja tudi, da izdelek ne vsebuje niti ene haram sestavine in med svojo izdelavo ni prišel v stik z ničemer, kar bi lahko bilo haram. To med drugim pomeni, da mora biti oprema, s katero se halal prehrana pripravlja, temeljito očiščena.

V Sloveniji za izdajo halal certifikatov skrbi Islamska skupnost v Republiki Sloveniji, pod okriljem katere deluje komisija za halal standarde. Halal certifikat ima 
tako več slovenskih podjetij (Perutnina Ptuj, Pivka, Kras, Panvita Agromekur, Mesnine dežele Kranjske, Pomurske mlekarne, Celjske mesnine, MP Alpe); osredotočena so sicer zlasti na tuji trg in v promocijo halal izdelkov ne vlagajo. $V$ javnosti so se pojavila tudi vprašanja, ali so certifikati usklajeni s slovensko zakonodajo, saj so izdani v arabskem in angleškem jeziku. Pravilno bi bilo, da bi bili izdani tudi v slovenščini (D. M. 2019). Ko smo o tem povprašali vodstvo Islamske skupnosti, so nam odgovorili (NOVA24 TV), da se izdelki izdelujejo za tuji trg, posledično so tudi podatki na njih zapisani v angleškem in arabskem jeziku.

Pridobitev halal certifikata je zahteven in dolgotrajen proces. Na našem geografskem področju igra vodilno vlogo Islamic International Documentation and Certification $\mathrm{GmbH}$ (IIDC), ki je mednarodna neodvisna internacionalna pooblaščena inšpekcija in obenem center za izdajanje halal certifikatov. Sedež ima v Avstriji. IIDC priznava, da so halal produkti v zadnjih petnajstih letih postali priljubljeni. Na njihovi spletni strani je opisan tudi postopek za pridobitev halal certifikata, ki se začne z oddajo prošnje. Po preverjanju ustreznosti halal izdelka glede na halal standarde se začne aplikacija. Če kakšen od zahtevkov ni izpolnjen, se prošnja zavrne oz. vrne $v$ dopolnitev. Ponovno sledi preverjanje in revizija poročila. Ko halal komite prošnjo odobri, inšpekcijska služba izda halal certifikat. Po pridobitvi halal certifikata je podjetjem dovoljeno, da na svoje izdelke natisnejo ustrezen logotip. Komisije naj bi redno skrbele za pregledovanje halal izdelkov in opreme ter pogojev, $v$ katerih so narejeni. Če določeno podjejte pogojev ne izpolnjuje več, se mu halal certifikat odvzame.

To se je zgodilo slovenskemu podjetju Košaki TMI (Malanović 2013). Švedski znanstveniki so namreč aprila 2013 ugotovili, da je bila v halal salami prisotna svinjina, ki jo je muslimanom prepovedano uživati. Svinjine naj bi bilo okoli $10 \%$, prepovedano pa je, da bi bila vsebnost v hrani več kot $1 \%$ (Šoštarič, 2013). Na to se je odzvala tudi Islamska skupnost, ki je sporočila, da jih je takratni direktor podjetja Košaki TMI Jure Bojnec že januarja obvestil, da podjetje ne more več omogočati pogojev za izdelovanje halal hrane in da v prihodnje teh produktov več ne bodo izdelovali. Kljub temu je koordinator za halal standarde izrazil ogorčenost muslimanov, saj do česa takega ne bi smelo priti (Škandal v zvezi z odkritjem švedskega laboratorija 2013).

$\checkmark$ pogovorih z muslimani smo večkrat slišali, da je ponudba halal izdelkov v Sloveniji slaba, le redke pa notranja želja po pravilnem prehranjevanju vodi v nakup halal izdelkov v tujini (zlasti v Avstriji, BiH in na Hrvaškem). Treba je omeniti, da se je v Sloveniji v zadnjih desetih letih izbor ponudbe halal izdelkov, ki pa ne zajema zgolj mesnin, povečal. Podjetje Jaffa pod halal certifikatom izdaja piškote Jaffa $v$ različnih okusih in piškote Munchmallov - piškoti tako vsebujejo rastlinsko želatino. Halal je tudi $A B C$ sveži kremni sirni namaz. Halal proizvode tujih proizvajalcev je mogoče kupiti v trgovinah E. Leclerc, Interspar, Mercator, Hofer in Tuš.

V Sloveniji sicer obstaja nekaj manjših halal mesnic, najbolj znana je Halalko v Ljubljani, ki ima vzpostavljeno tudi e-trgovino. Delovati je začela 19. junija 2008 (Osredkar 2011, 94). Halal meso za kebabe proizvaja kranjsko podjetje Halal Guda 
Doner Kebap, s katerim sodeluje ljubljanski FM Center d. o. o. V Ajdovščini je halal izdelke možno kupiti v trgovini Su-sud. Znotraj Slovenske muslimanske skupnosti $^{1}$ je registrirano podjetje Halal d. o. o., Halal družba za trgovino in posredništvo. Leta 2018 se je na Zaloški cesti v Ljubljani odprla turška trgovina Atlas, ki prav tako ponuja halal izdelke. V Novi Gorici, Ajdovščini, Velenju, Jesenicah, Kopru in Ljubljani je mogoče najti tudi kioske s halal ponudbo.

Muslimani, ki se izpolnjevanja verske prakse držijo bolj dosledno, v Sloveniji pogrešajo restavracijo, v kateri ne bi bilo haram hrane. Očitno nekateri muslimani v Sloveniji ponudbe halal restavracij ne poznajo dovolj dobro, saj nihče izmed vprašanih obiska teh restavracij ni omenil. Večina jih zunaj jé vegetarijansko hrano, preventivno izbirajo tudi veganske in suši restavracije - a zadnje le pod pogojem, da se pri ribah ne ozirajo na postopek zakola. Drži pa, da je vseh devet slovenskih restavracij, ki imajo halal certifikat, v osrednjeslovenski regiji. Od tega jih je osem v Ljubljani (Behar, Safran, Saraj restavracija, Arabska restavracija Habibi, Yildiz Han, Šeherezada, Fari's, Dunaya Doner), ena pa v Kamniku (Tsnim restavracija).

\section{Zaupanje v halal proizvodnjo v tujini}

Preden na primerih predstavimo, kakšno je zaupanje v halal proizvodnjo v tujini, je treba opredeliti, kaj je na porast halal industrije in njeno prodajno moč vplivalo. Strokovnjaki za tovrstno področje menijo, da je halal hrana predvsem bolj kakovostna, njeno poreklo je bolj pregledno, poleg tega pa naj bi zahtevni postopki za pridobitev halal certifikatov pripomogli k večjemu zaupanju ljudi v halal proizvode.

Po drugi strani Gojali (2020) meni, da je v posameznih državah zaupanje v halal industrijo in proizvode s halal certifikatom različno. Na to vpliva tudi, da nekatere nemuslimanske države veljavna pravila spreminjajo. V Avstraliji za pridobitev halal certifikatov ni treba izpolnjevati pogoja, da moral biti žival zaklana po islamskih predpisih, klanje živali po verskih predpisih pa je prepovedano v Belgiji, Islandiji, na Norveškem, Švedskem in Danskem. Koen De Praetere (v Rarick idr., 2012, 84) pravi, da v Evropi mnogim podjetjem, ki se ukvarjajo s halal industrijo, bolj diši denar kot pa pošteno delo. Tako v Evropi kot tudi v islamskih državah (npr. Pakistan) potrošniki veliko raje kupujejo dražje meso pri lokalnih mesarjih kot pa cenejše izdelke s halal certifikatom (Bonne in Verbeke 2006; Yunos, Balish in Che 2017).

Yunos (2017) je na podlagi raziskave, opravljene v Maleziji, ki v halal industriji velja za vodilno državo, ugotovil, da večje kot je zaupanje v halal izdelke, več denarja so muslimani pripravljeni zanje odšteti. Prav tako ugotavlja, da halal izdelkom bolj zaupajo muslimani z višjo stopnjo izobrazbe. Isti avtor tudi omenja, da je najpogostejši dejavnik za nakup halal izdelkov religioznost, sledijo mu zadovoljstvo, subjektivne norme, halal certifikati, interes, zaupanje in na zadnjem mestu halal ozaveščenost.

V Sloveniji so registrirane tri islamske verske skupnosti: Islamska skupnost v Republiki Sloveniji, Slovenska muslimanska skupnost, Slovenska islamska skupnost milosti. 


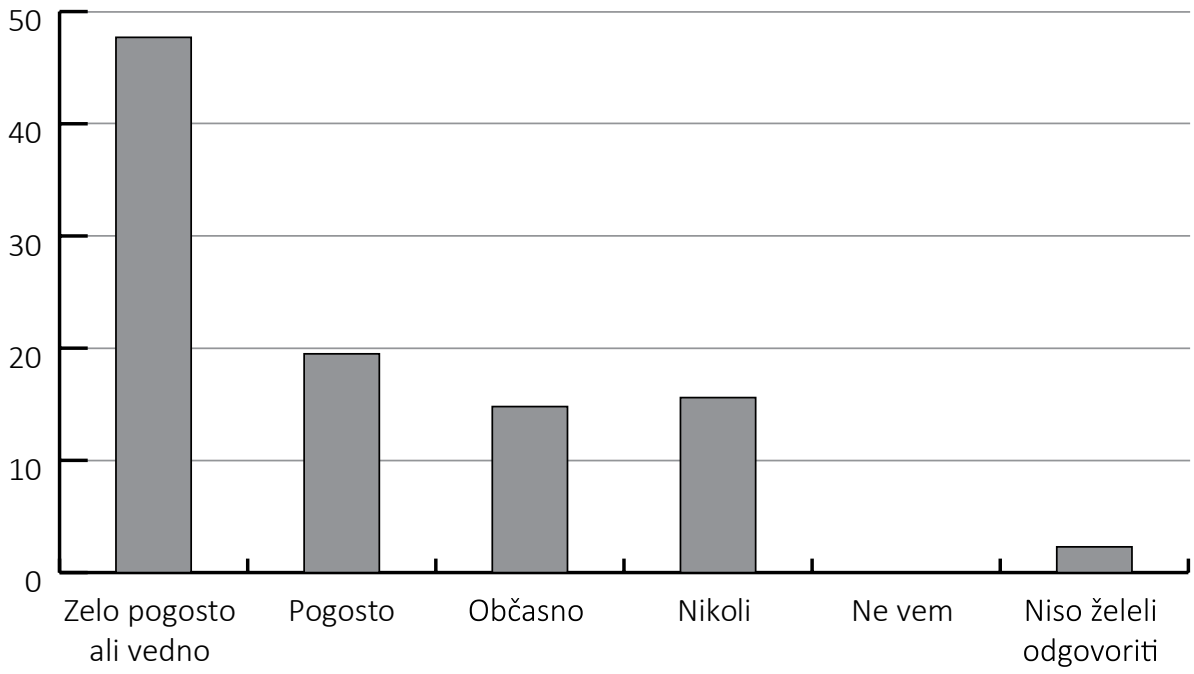

Graf 1: Pogostost prehranjevanja po halal predpisih pri muslimanih v Republiki Sloveniji. ${ }^{2}$

Kljub zgoraj omenjenemu pa ne moremo prezreti dejstva, da trg halal industrije bliskovito narašča. Leta 2019 je bil trg certificiranja živil ocenjen na 14,55 milijarde ameriških dolarjev. Napovedi kažejo, da naj bi halal proizvodnja živil ob rasti s stopnjo CAGR 4,9 \% do leta 2025 dosegla 19,36 milijarde ameriških dolarjev. Halal industrija sicer ne zajema le prehranjevalne verige, ampak tudi kozmetiko, zdravila, čistila in tekstilno industrijo.

\section{Muslimani v Sloveniji in halal prehrana}

Prehranjevanje po halal predpisih je prisotno tudi pri slovenskih muslimanih - najbolj so sicer pozorni na prehrano, medtem ko pri kozmetiki in zdravilih ne pazijo zelo, ali so zares halal. Pri tem v slovenskih lekarnah zdravil s halal oznako niti ni možno kupiti, farmacevti pa trdijo, da do sedaj po tem še ni bilo nobenih povpraševanj.

Graf 1 (spodaj) prikazuje, kako pogosto se muslimani v Sloveniji prehranjujejo po islamskih predpisih. $V$ intervjujih z imami in nekaterimi islamskimi verniki smo ugotovili, da se nekateri muslimani predpisov halal prehranjevanja ne držijo. Opažamo tudi, da nekateri muslimani sicer ne jedo svinjine, pijejo pa alkohol, drugi pa ravno obratno. Na podlagi opravljene raziskave o prehranjevanju s halal izdelki lahko muslimane $v$ Sloveniji razdelimo na tri skupine: a) muslimane, ki se predpisov halal prehranjevanja držijo; b) muslimane, ki ne jedo svinjine in ne pijejo alkohola, a izdelkov s halal certifikatom ne kupujejo; c) muslimane, ki kupujejo izdelke s halal certifikatom.

2 Anketna raziskava je bila narejena v okviru doktorske disertacije leta 2020. 
Prvo okolje, v katerem se otrok sreča s halal prehrano, je družina. Ko odrastejo, lahko nekateri muslimani družinsko tradicijo - in s tem halal prehranjevanje opustijo ali pa se sami začnejo prehranjevati po halal predpisih, čeprav se njihovi starši niso. Vpliva družinske tradicije torej ne gre zanemariti. Človek preko tradicije podoživlja različne spomine (pogosto vezane na mladost) in skoznjo doživlja množico časov (Nežič Glavica 2019, 196). Vodičar $(2020,262)$ dodaja, da slednji "daje priučenim navadam določeno težo avtoritete in odprtosti. « Hkrati sledenje tradiciji prinaša večjo samozavest in naposled trdnejšo predstavo o svojem moralnem in epistemološkem položaju v utelešenih in zgodovinskih kontekstih.

Takšna odločitev je pogosto povezana z osebno vero in pravno šolo, ki ji sledijo. Muslimani, ki izpolnjujejo halal predpise bolj dosledno, so po navadi strožji tudi pri izpolnjevanju drugih verskih predpisov - pogosteje molijo in se postijo. $\mathrm{Na}$ prehranjevanje po halal predpisih vpliva tudi to, kateri generaciji priseljencev verniki pripadajo in katero pot prilagoditve življenja so izbrali (asimilacija, integracija, segregacija), kakor tudi navade, ki so veljale v krajih njihovega izvora.

Muslimani v Sloveniji so že večkrat opozorili na nerešena vprašanja glede možnosti nudenja halal obrokov v javnih ustanovah, predvsem v vzgojno-izobraževalnih zavodih. Ker omenjeno področje v Sloveniji ni pravno urejeno, so izkušnje posameznikov različne, prav tako se lahko vsaka vzgojno-izobraževalna ustanova sama odloči, ali bo muslimanskim vernikom možnost halal obroka omogočila - in pod kakšnimi pogoji. Grabus (Grah 2014) je omenjeno situacijo povzel z besedami:

»Po drugi strani imamo v islamski skupnosti notranji problem. To je strah, ki je močno razširjen med muslimanskimi starši. Zaradi strahu si problema prehrane v šoli niti ne upajo načeti. O njem ne govorijo, ker se bojijo stigmatizacije. Stigmatizacija muslimanov je večji problem kot to, kdaj bodo otroci jedli šolsko malico brez svinjskega mesa. Hkrati si ne gre zatiskati oči pred tem, da je precej muslimanskih staršev že popolnoma asimiliranih in niti ne pomislijo, da bi uživanje svinjskega mesa lahko bilo sporno. Del muslimanov pa to težavo ima in najbolje jo je reševati na osebni ravni. Zato pozivam odgovorne v vrtcih in šolah, naj razumejo, da gre za vprašanje vrednot.»

\section{Zaupanje $\mathbf{v}$ halal izdelke in halal proizvodnjo pri muslimanih v Sloveniji}

V prispevku smo želeli pokazati, kakšno je zaupanje muslimanov v Sloveniji v halal proizvodnjo in halal industrijo. Ugotavljamo, da lahko muslimane, ki se prehranjujejo po halal predpisih in kupujejo halal izdelke (zgoraj omenjena kategorija c), razdelimo $v$ tri skupine. $V$ prvo skupino spadajo muslimani, ki zaupajo tako slovenskim kot tujim proizvajalcem halal izdelkov. Naslednja kategorija muslimanov zaupa le halal izdelkom iz tujine. Zadnja skupina muslimanov, ki uporablja halal prehrano, pa zaupa zgolj sama sebi in ozkemu krogu ljudi, zato si živali za zakol priskrbi sama in obredno klanje živali tudi sama organizira. Ta pristop je najbolj značilen za salafite. 
Muslimani, ki zaupajo tako slovenskemu kot tujemu halal trgu, so pri svojih nakupih najbolj pozorni na to, da imajo izdelki halal logotip. Veliko jih kupuje ali naroča hrano tudi v halal mesnici. Po pogovorih z muslimani predvidevamo, da je tovrstna skupina najmočnejša. S tem ali je izdelek resnično halal ali ne, si ne belijo glave. Po islamskem učenju musliman, ki zaužije haram hrano v nevednosti, ne greši. Hkrati muslimani v Sloveniji omenjajo, da se v večjih krajih halal ponudba širi. $V$ eni izmed velenjskih trgovin Spar npr. režejo mesnine z ločenimi mesoreznicami in noži - tako poskrbijo, da halal meso ne pride v stik s svinjino.

Druga skupina muslimanov, ki se prehranjuje po halal predpisih, zaupa zgolj tujemu trgu. Hrano najpogosteje nakupujejo v Avstriji, Italiji, na Hrvaškem ter v Bosni in Hercegovini. Najpogostejši razlog za to je slabo razvit halal trg na slovenskih tleh, zaradi česar da obstaja tudi večja možnost za kršitve. Člani Slovenske muslimanske skupnosti in Slovenske islamske skupnosti milosti izražajo tudi dvome v pravilnost upoštevanja halal standardov, ki jih izdaja Islamska skupnost v Republiki Sloveniji. Na tem mestu je treba omeniti, da so v ozadju večkrat osebni razlogi in a priori nasprotovanja med različnimi muslimanskimi skupnostmi v Sloveniji.

Muslimani v Sloveniji večinoma sledijo hanifejski pravni šoli. Manjšina (tudi npr. Slovenska islamska skupnost milosti) sledi salafitski pravni šoli, ki priznava le nauk prvih treh generacij. Njihovo učenje je konzervativno, izpolnjevanje verske prakse doslednejše, toleriranje odstopanj pa skorajda nično. To se odraža tudi pri zaupanju v halal industrijo. Zadnja skupina muslimanov slovenskim in tujim certifikatom težko zaupa, saj jim podjetja ne omogočajo popolnega pogleda v pridobivanje porekla o izdelkih. Predvsem mesnine tako kupujejo pri lokalnih, preverjenih muslimanskih kmetih ali pa si živali celo sami redijo in jih nato sami tudi obredno zakoljejo. Omenjena skupina muslimanov je v Sloveniji najmanj številčna.

\section{Reference}

Bonne, Karijin, in Wim Verbeke. 2006. Muslim consumer's motivations towards meat consumption in Belgium: Qualitative exploratory insights from means-end chain analysis. Anthropology of Food 5:1-24.

Gojali, Dudang in Vemy Suci Asih. 2020. Determinant factors of Indodenesian Muslim behaviour in choosing halal products. Innovative Marketing 16, št.4:155-163.

Grabus, Nedžad. 2011. Sožitje je naša pot: Intervjuji in govori muftija dr. Nedžada Grabusa. Ljubljana: Kulturno-izobraževalni zavod Averroes.

Islamska skupnost v Republiki Sloveniji. 2013. Domača stran. April. https://www.islamska-skupnost.si/2013/04/sporocilo-za-javnost-v-zvezi-s-halal-standardom/ (pridobljeno 3. 8. 2021).

Khader, Bichara. 2016. Muslims in Europe or European Muslims? The construction of a problem. Rivista di Studi Politici Internazionali 83, št. 2:169-187.

Koran. 2005. Prevedel Erik Majaron. Tržič: Učila International.

Nežič Glavica, Iva. 2019. Vloga izkustvenega učenja v geštaltpedagoškem modelu učenja in poučevanja po Albertu Höferju. Bogoslovni vestnik 79, št. 1:191-202.

Nova 24TV. 2019. Islamska skupnost v RS slovenskim podjetjem izdaja, halal certifikate' $v$ arabščini in angleščini, o slovenščini ne duha ne sluha. Domača stran, 16. 6. https://nova24tv.si/slovenija/islamska-skupnost-v-rs-slovenskim-podjetjem-izdaja-halal-certifikate-v-arabscini-in-anglescini-o-slovenscini-ne-duha-ne-sluha-povprasali-smo-znane-odvetnike-ce-je-to-dovoljeno/ (pridobljeno 24. 4. 2020). 
Osredkar, Mari Jože. 2011. Verska integracija muslimanov v Sloveniji. V: Janez Malačič in Matjaž Gams, ur. Soočenje z demografskimi izidi v Evropi: zbornik 14. mednarodne multikonference Informacijska družba - IS 2011, 10.-11. oktober 2011, 90-95. Ljubljana: Inštitut Jožef Štefan.

- - . 2019. Religija kot izziv za transhumanizem. Bogoslovni vestnik 79, št. 3:657-668.

Pollak, Senja. 2007. Prehrambene prepovedi v judovstvu, krščanstvu in islamu. Diplomska naloga. Univerza v Ljubljani, Filozofska fakulteta.

Rarick, Charles A., Casimir Barczyk, Lori Feldaman in G. Falk. 2012. Marketing to Muslims: The Growing Importance of Halal Products. Economics Journal of the International Academy of Case Studies 18, št. 1:81-86.

Shahab, Ahmed. 2017. What is Islam? The importance of being Islamic. Princeton: Princeton University Press.

Slovenska muslimanska skupnost. 2013. Vprašanja za direktorja Košakov. Domača stran, 10. 5. http://www.smskupnost.si/index. php?option=com_content $\&$ task=view $\&$ id $=719$ \&ltemid=2 (pridobljeno 23. 4. 2020).

Šoštarič, Marjeta. 2013. Švedi v slovenski salami halal odkrili svinjino. Delo, 10. 3. https://www. delo.si/gospodarstvo/finance/svedi-v-slovenski-salami-halal-odkrili-svinjino.html (pridobljeno 30. 3. 2016).

Vodičar, Janez. 2020. Kritika sekularizacije: tradicija pot do trdožive prihodnosti. Bogoslovni vestnik 80 , št. 2:253-266.

Yunos, Rahimah Mohamed, Zakira Nor Balkish in Mahmood Che Fardih Che. 2017. Trustworthiness of halal products among Muslim consumers. Neobjavljeni prispevek na konferenci. https://www.researchgate.net/publication/320407133_Trustworthiness_of_halal_ products_among_Muslim_consumers (pridobljeno 7. $\overline{5} .2021)$. 